\title{
Transition from Reversible to Persistent Binding of CaMKII to Postsynaptic Sites and NR2B
}

\author{
K. Ulrich Bayer, ${ }^{1}$ Éric LeBel, ${ }^{2,3}$ Greg L. McDonald, ${ }^{2,4}$ Heather 0'Leary, ${ }^{1}$ Howard Schulman, ${ }^{5}$ and Paul De Koninck ${ }^{2,3}$ \\ ${ }^{1}$ Department of Pharmacology and Program in Neuroscience, University of Colorado Health Sciences Center, Denver, Colorado 80262, ${ }^{2}$ Centre de Recherche \\ Université Laval Robert-Giffard, Québec, Canada G1J 2G3, Departments of ${ }^{3}$ Biochemistry and Microbiology and ${ }^{4}$ Physics, Laval University, Québec, Canada \\ G1K 7P4, and ${ }^{5}$ Department of Neurobiology, Stanford University, Stanford, California 94305-5125
}

Changes in protein-protein interactions and activity states have been proposed to underlie persistent synaptic remodeling that is induced by transient stimuli. Here, we show an unusual stimulus-dependent transition from a short-lived to long-lasting binding between a synaptic receptor and its transducer. Both molecules, the NMDA receptor subunit NR2B and $\mathrm{Ca}^{2+} / \mathrm{calmodulin}(\mathrm{CaM})-$ dependent protein kinase II (CaMKII), are strongly implicated in mediating synaptic plasticity. We show that CaMKII reversibly translocates to synaptic sites in response to brief stimuli, but its resident time at the synapse increases after longer stimulation. Thus, CaMKII localization reflects temporal patterns of synaptic stimulation. We have identified two surface regions of CaMKII involved in short-lived and long-term interactions with NR2B. Our results support an initial reversible and $\mathrm{Ca}^{2+} / \mathrm{CaM}$-dependent binding at the substratebinding site ("S-site"). On longer stimulation, a persistent interaction is formed at the T286-binding site ("T-site"), thereby keeping the autoregulatory domain displaced and enabling $\mathrm{Ca}^{2+} / \mathrm{CaM}$-independent kinase activity. Such dual modes of interaction were observed in vitro and in HEK cells. In hippocampal neurons, short-term stimulation initiates a reversible translocation, but an active history of stimulation beyond some threshold produces a persistent synaptic localization of CaMKII. This activity-dependent incorporation of CaMKII into postsynaptic sites may play a role in maturation and plasticity of synapses.

Key words: kinase; synapse; plasticity; glutamate; calcium; NMDA receptor

\section{Introduction}

Compartmentalization of signaling pathways can enhance their specificity and efficiency. The postsynaptic density (PSD) is an organized compartment of structural and signaling proteins at excitatory synapses. Remodeling of the PSD is believed to cause long-term changes in synaptic transmission, which are assumed to underlie learning and memory. Two PSD proteins have been especially recognized as important mediators of synaptic plasticity: the NMDA-type glutamate receptor (NMDAR) and the $\mathrm{Ca}^{2+} /$ calmodulin (CaM)-dependent protein kinase II (CaMKII) (Silva et al., 1992; Malenka and Nicoll, 1999; Kennedy, 2000; Lisman and McIntyre, 2001; Lisman et al., 2002; Colbran and Brown, 2004; Griffith, 2004).

The association of CaMKII with the PSD has been postulated to be important for synaptic functions of the kinase. CaMKII can

Received July 27, 2005; revised 0ct. 17, 2005; accepted Nov. 29, 2005.

This work was supported by American Heart Association Grant SDG 0430196N (K.U.B.) and by the Canadian Institutes of Health Research (CIHR) and the National Alliance for Research on Schizophrenia and Depression (P.D.K.) E.L. is supported by CIHR and the K. M. Hunter Foundation, G.L.M. is supported by the NeuroPhysics Strategic Training Program from CIHR, and P.D.K. was supported by Career Awards from the Burroughs Wellcome Fund and the Fonds de la Recherche en Santé du Québec. The excellent technical assistance of Francine Nault and Salma Behna is gratefully acknowledged. We thank Drs. Mark Dell'Acqua, Mair Churchill, and Karen Smith (University of Colorado Health Sciences (enter) for critical reading of this manuscript.

Correspondence should be addressed to K. Ulrich Bayer, Department of Pharmacology, University of Colorado Health Sciences Center, P.0. Box 6511, Mail Stop 8303, Aurora, C0 80045. E-mail: ulli.bayer@uchsc.edu.

H. Schulman's present address: PPD Biomarker Discovery Sciences, Menlo Park, CA 94025.

D0I:10.1523/JNEUROSCI.3116-05.2006

Copyright $\odot 2006$ Society for Neuroscience $\quad$ 0270-6474/06/261164-11\$15.00/0 bind to several PSD proteins in vitro, including NR2B, NR2A, NR1, and densin-180 (Strack and Colbran, 1998; Gardoni et al., 1999; Strack et al., 2000b; Bayer et al., 2001; Walikonis et al., 2001; Leonard et al., 2002). However, the relative contribution of each interaction to synaptic localization and function is not clear (for review, see Bayer and Schulman, 2001; Colbran, 2004). These synaptic protein-protein interactions are regulated by CaMKII autophosphorylation at T286, but in the case of NR2B, $\mathrm{Ca}^{2+} /$ CaM alone is sufficient to induce CaMKII binding (Bayer et al., 2001). Synaptic translocation of CaMKII induced by NMDAR stimulation similarly requires $\mathrm{Ca}^{2+} / \mathrm{CaM}$ activation but not T286 phosphorylation. This interaction was described to be completely reversible (Shen and Meyer, 1999; Shen et al., 2000); however, chemical long-term potentiation (LTP) induction resulted in CaMKII translocation to spines that persisted for at least 90 min (Otmakhov et al., 2004).

In a simple LTP model, CaMKII is activated by $\mathrm{Ca}^{2+}$-influx through NMDARs and potentiates synaptic strength by enhancing AMPA-type glutamate receptor (AMPAR) currents (Benke et al., 1998; Derkach et al., 1999; Hayashi et al., 2000; Zhu et al., 2002). Generation of persistent autonomous ( $\mathrm{Ca}^{2+} / \mathrm{CaM}-$ independent) CaMKII activity at synapses has been proposed to be central in long-lasting plasticity (for review, see Chen et al., 2001; Lisman and McIntyre, 2001; Lisman et al., 2002). CaMKII autonomy can be generated by two different mechanisms: the classical intersubunit autophosphorylation at T286 or by binding to NR2B (Bayer et al., 2001). The autophosphorylation- 
dependent form of autonomy is reversed by phosphatase activity, whereas autonomy of the NR2B-bound enzyme should only terminate after dissociation from NR2B. Thus, long-lasting CaMKII autonomy at synapses could be generated by reducing T286directed phosphatase activity (Strack et al., 1997; Fukunaga et al., 2000) or by maintaining CaMKII binding to NR2B.

We show here that glutamate/glycine-induced translocation of green fluorescent protein (GFP)-CaMKII to synapses in cultured hippocampal neurons exhibited a reversible and a persistent component, which paralleled CaMKII binding to NR2B in vitro and in HEK cells. We demonstrate a novel transition from a reversible to a persistent binding with longer stimulation. Our data support a model that involves successive binding to two different sites on CaMKII (S-site and T-site). We propose that strong synaptic stimulation results in persistent CaMKII incorporation into synapses via NR2B binding, allowing for longlasting autonomous activity in the PSD that may be important in plasticity.

\section{Materials and Methods}

Cell culture and transfection. Human embryonic kidney (HEK) cells were cultured and transfected with GFP-CaMKII constructs (kindly provided by Tobias Meyer, Stanford University, Stanford, CA) as described previously (Bayer et al., 2001). Neurons were cultured and transfected using Lipofectamine 2000 (Invitrogen, San Diego, CA) for $5 \mathrm{~h}$ as described previously (Hudmon et al., 2005) using GFP-CaMKII constructs with an A207K mutation in the GFP to eliminate its dimerization (Zacharias et al., 2002).

Time-lapse imaging of CaMKII translocation. Transfected HEK cells were imaged as described previously (Bayer et al., 2001) under perfusion with 25 mM HEPES, pH 7.4, buffered HBSS. $\mathrm{Ca}^{2+}$ stimuli were induced by adding $10 \mu \mathrm{M}$ ionomycin and $2 \mathrm{mM} \mathrm{CaCl}_{2}$ to the perfusion solution, whereas $1 \mathrm{~mm}$ EGTA was added to the washout solution.

Coverslips of transfected neurons were placed in a low-volume perfusion $(\sim 1 \mathrm{ml} / \mathrm{min})$ chamber (SD Instruments, Grants Pass, OR) on an Axioskop FS2 microscope with 63× “Achroplan" water immersion objective (Zeiss, Göttingen, Germany) equipped with multivalve perfusion system (PTR-2000; ALA-Scientific, Westbury, NY). Images (six and two per minute during stimulation and washout, respectively) were acquired with a CCD camera (CoolSnap-HQ; Photometrics, Tuscon, AZ) controlled by MetaMorph software (Molecular Devices, Downingtown, PA). Standard imaging solution consisted of $0.87 \times$ HBSS, 10 mM HEPES, $\mathrm{pH}$ 7.4, $2.0 \mathrm{~mm}$ glucose, $1.2 \mathrm{~mm} \mathrm{CaCl}_{2}$, and $1.0 \mathrm{~mm} \mathrm{MgCl}_{2}$ (osmolarity, 260 $\mathrm{mOsm})$. Stimulation solution additionally contained glutamate/glycine $(100 \mu \mathrm{M} / 10 \mu \mathrm{M})$ or NMDA/glycine $(30 \mu \mathrm{M} / 10 \mu \mathrm{M}$; data not shown), and washout solution contained low $\mathrm{Ca}^{2+} /$ high $\mathrm{Mg}^{2+}(0.6 \mathrm{~mm} / 5 \mathrm{~mm})$.

Immunocytochemistry. Transfected cells were fixed and immunostained as described previously (Bayer et al., 2001) using the PSD95 antibody IC9 (1:250; Affinity Bioreagents, Golden, CO) and G $\alpha \mathrm{M}$ Alexa546 (1:500; Invitrogen) as secondary antibody. Coverslips were mounted in Immunofluore mounting solution (ICN Biochemicals, Costa Mesa, CA) and imaged on a Zeiss LSM510 META-Axioskop FS2 Plus confocal system using a $63 \times$ oil immersion objective (PlanApochromat; Zeiss). GFP was excited with an Argon laser at $488 \mathrm{~nm}$ and detected through a bandpass filter (505-535 nm). Alexa 546 was excited with a HeNe laser at 543 and detected through a long-pass filter $(560 \mathrm{~nm})$.

Quantification of CaMKII synaptic translocation. We used two complementary approaches to quantify CaMKII postsynaptic localization. First, neurons were stimulated and fixed immediately, processed for PSD95 immunostaining, and observed under the microscope. Transfected neurons were scored, blind to the condition, for the fluorescence contrast between synaptic areas (PSD95 positive) and the rest of the dendrites on a scale of "-" to " ++++ " (see image samples in Fig. 6 and supplemental Fig. 1, available at www.jneurosci.org as supplemental material). This approach, validated previously (Hudmon et al., 2005), afforded the collection of a large data set ( $>100$ neurons per mutant) to screen the effect of different mutations or long-lasting incubation conditions (see Fig. 1). Second, for quantification of time-lapse experiments, in-house software was developed in IDL (RSI, Boulder, CO) to automate measurements of the contrast between synaptic and neighboring extrasynaptic pixels on dendrites from a series of images. Each 12-bit (0-4095) image of a series was first background-corrected and the soma manually masked out. A sliding threshold ranging from the image minimum to maximum values in increments of 20 was applied. To detect above-threshold groups of contiguous pixels that corresponded to synapses, we used two criteria: pixel area corresponding to $0.22-0.45 \mu \mathrm{m}^{2}$ and shape factor $\left(4 \pi \mathrm{A} / \mathrm{P}^{2} ; \mathrm{A}\right.$, area; $\mathrm{P}$, perimeter $)>0.6$. The algorithm identified relatively few apparently nonsynaptic objects (based on PSD95 costaining of fixed neurons). The "synaptic contrast" is [(mean pixel intensity of each object) (threshold value at which it was detected)]/(mean value of all nonzero pixels in the image), averaged over all objects. To evaluate the dissociation rates of CaMKII from postsynaptic sites, the mean synaptic contrast over the $2 \mathrm{~min}$ before stimulation was rescaled to zero (referred to as "relative postsynaptic localization") (see Fig. 9A); additionally, the mean at the peak of translocation was rescaled to one (referred to as "postsynaptic localization index") (see Figs. 2B, 9B).

Binding to immobilized glutathione S-transferase fusion proteins. A glutathione $S$-transferase (GST) fusion protein with the cytoplasmic C-terminal portion of NR2B (1120-1482; NR2B-C) was immobilized on anti-GST-coated 96-well plates (Amersham Biosciences, Piscataway, NJ). CaMKII binding was assessed by immunoblotting or biotinylated calmodulin overlay of the bound protein after elution from the wells (Bayer et al., 1998, 2001). Unless indicated otherwise, binding time was $45-60 \mathrm{~min}$ at $4^{\circ} \mathrm{C}$ in PIPES, pH 7.2, buffered saline in the presence of $\mathrm{Ca}^{2+} / \mathrm{CaM}$, followed by seven washes over a time of $\geq 15 \mathrm{~min}$ in buffer containing $1 \mathrm{~mm}$ EGTA instead of $\mathrm{Ca}^{2+} / \mathrm{CaM}$. However, some experiment (see Fig. 3) binding was done at room temperature, followed by four quick rinses within $20 \mathrm{~s}$. For binding of CaMKII $\alpha$ wild-type, purified protein from a baculovirus/Sf9 cell overexpression system was used (Singla et al., 2001; Bradshaw et al., 2002); for binding of the isoforms and mutants, $20,000 \times g$ supernatants of transfected Cos7 cells were used (Bayer et al., 1998).

CaMKII activity. Kinase activity was assessed by ${ }^{32} \mathrm{P}$ incorporation into the peptide substrate AC3, as described previously (Bayer et al., 2001). Full-length and truncated (1-316) CaMKII $\alpha$ purified from a baculovirus/Sf9 cell overexpression system was used. The peptides N2B-1 (NR2B 1259-1310) or N2B-s (NR2B 1289-1310) were incubated with the kinase in the presence of $\mathrm{Ca}^{2+} / \mathrm{CaM}$ to initiate interaction. To allow dissociation of $\mathrm{Ca}^{2+} / \mathrm{CaM}$, EGTA was added $4 \mathrm{~min}$ before the mix was diluted 1:5 into the activity assays.

\section{Results}

\section{Synaptic CaMKII localization reflects past neuronal stimulation}

GFP-CaMKII $\alpha$ was found at synapses of unstimulated hippocampal neurons [12-14 d in vitro (DIV)] $16 \mathrm{~h}$ after transfection, as indicated by immunostaining of PSD95 as a synaptic marker (Fig. 1A). This spontaneous synaptic localization appeared persistent and was not reversed by perfusing the neurons with low $\mathrm{Ca}^{2+} /$ high $\mathrm{Mg}^{2+}$ external solution for $30 \mathrm{~min}$ (data not shown). However, when NMDARs were blocked in the cultures by AP-5 directly after transfection, GFP-CaMKII $\alpha$ was much more evenly distributed throughout the neurons (Fig. $1 B$ ). Using a semiquantitative analysis (supplemental Fig. 1, available at www.jneurosci.org as supplemental material), we estimated the percentage of neurons that exhibited synaptically enriched CaMKII to be approximately threefold lower in the presence of AP-5 (Fig. 1C). The $\mathrm{Ca}^{2+} / \mathrm{CaM}$ binding-deficient CaMKII $\alpha$ mutant T305/306D was also more evenly distributed, even in absence of AP-5 (Fig. 1C). This indicated that $\mathrm{Ca}^{2+} / \mathrm{CaM}$ activation of CaMKII by NMDAR stimulation via spontaneous synaptic activity in the culture was necessary and sufficient to induce persistent synaptic localization of CaMKII. The 

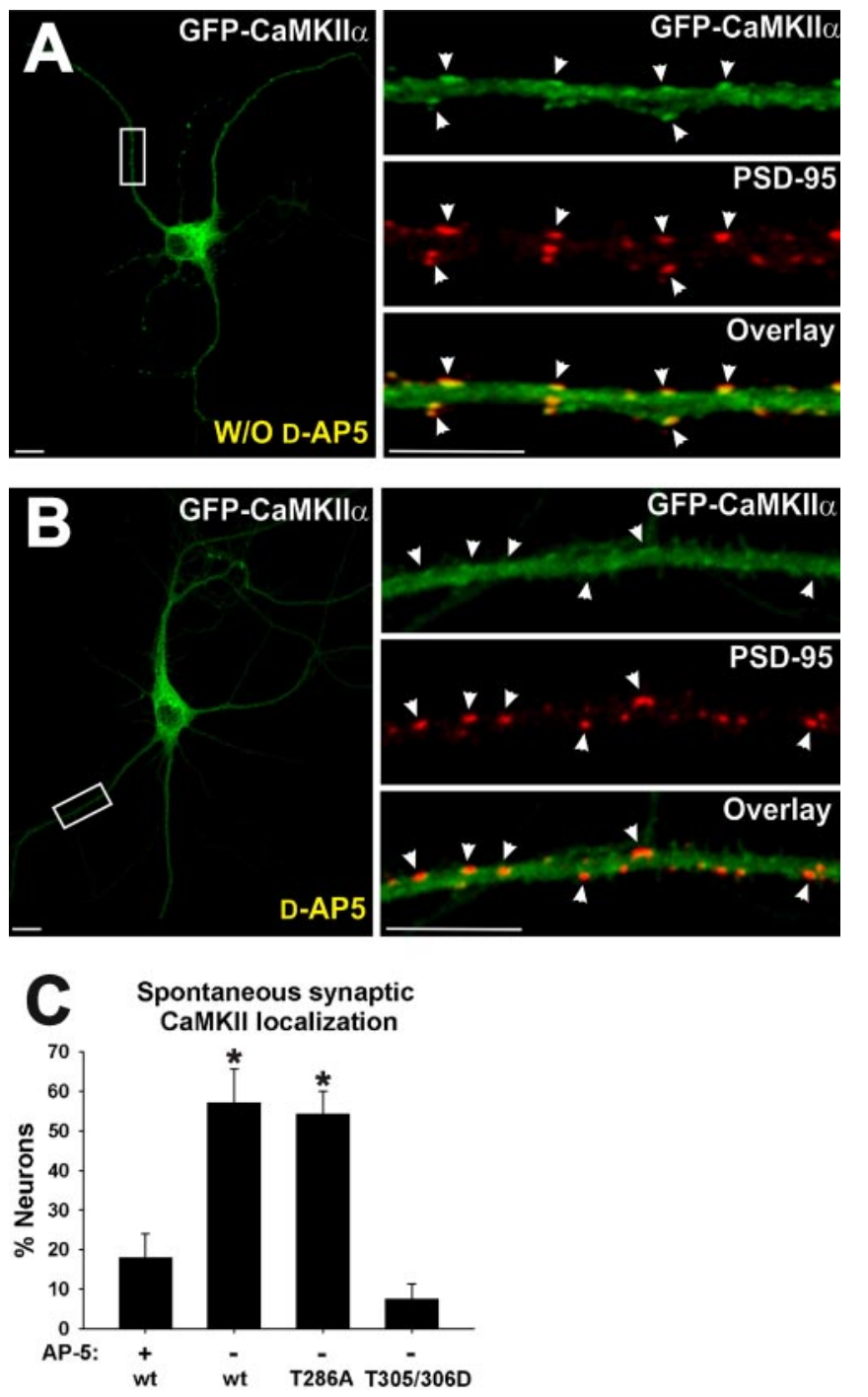

Figure 1. Spontaneous postsynaptic CaMKIl $\alpha$ localization in hippocampal neurons (12-14 DIV). $\boldsymbol{A}, \boldsymbol{B}$, Spontaneous synaptic enrichment of CaMKIl $\alpha$ depends on NMDAR activity. Neurons expressing GFP-CaMKII $\alpha$ were incubated without $(\boldsymbol{A} ; \mathrm{W} / 0)$ or with $(\boldsymbol{B}) 100 \mu \mathrm{M} \mathrm{AP}-5$ for $16 \mathrm{~h}$, fixed, and immunostained for PSD95. Boxes indicate cropped area on the right. Arrowheads indicate synaptic sites. Colocalization was more pronounced in untreated neurons. Scale bars: overview, $10 \mu \mathrm{m}$; cropped, $5 \mu \mathrm{m}$. C, Mean percentage ( \pm SEM; $n=3$ ) of neurons (78-93 per $n$ ) exhibiting synaptic enrichment of GFP-CaMKII $\alpha$ (neurons with localization score of " + " or more; see Materials and Methods). Neurons were transfected with wild-type (wt) or T305/306D GFP-CaMKII $\alpha$. The asterisk indicates significantly different from T305/306D ( ${ }^{*} p<0.01 ; t$ test).

autophosphorylation-defective mutant of CaMKII $\alpha$ (T286A) was localized synaptically in the absence of AP-5 (Fig. 1C), indicating that T286 phosphorylation was not required for the persistent postsynaptic recruitment of the enzyme (Shen and Meyer, 1999).

To examine whether acute NMDAR stimulation also leads to persistent postsynaptic localization, AP-5 pretreated neurons were stimulated by bath application of NMDA (data not shown) or glutamate/glycine (Fig. $2 \mathrm{~A}$ ) in the absence of AP-5 for $1 \mathrm{~min}$. This treatment induced robust translocation of GFP-CaMKII $\alpha$ to synapses (Fig. 2A) (supplemental Fig. 1, available at www. jneurosci.org as supplemental material). Quantitative analysis of this rapid postsynaptic translocation revealed that it was, for the most part, reversed within 2 min of perfusion with low $\mathrm{Ca}^{2+}$ / high $\mathrm{Mg}^{2+}$ external solution (Fig. $2 \mathrm{~B}$ ). However, a significant amount of kinase ( $\sim 20 \%$ of peak translocation) remained per- sistently localized at synapses even after $30 \mathrm{~min}$ of washout (Fig. $2 B$ ) (supplemental movie, available at www.jneurosci.org as supplemental material). Again, the T286A mutant of CaMKII $\alpha$ also exhibited both the peak and the long-lasting plateau of postsynaptic localization. However, its initial phase of dissociation from the synapse after washout was significantly faster compared with wild-type (Fig. 2B), as described previously (Shen and Meyer, 1999).

We next tested whether the duration of the stimulation would affect the dissociation time course of CaMKII from the synapse. The most significant effect of stimulation time was on the height of the persistent plateau (between 5 and 26 min of wash). The relative amount of persistently synaptic CaMKII during this prolonged washing phase increased with stimulation time, both for wild-type and T286A (Fig. 2C). These results suggest that the extent of persistent synaptic CaMKII localization reflects the past neuronal stimulation history. The stimulus-dependent transition from reversible to persistent synaptic CaMKII localization does not depend on T286 autophosphorylation, because it was also seen for the T286A mutant. However, T286 autophosphorylation appears to modulate the transition, because the height of the persistent plateau was significantly lower for T286A than for wild-type CaMKII, at least after 2 min of stimulation (Fig. 2C).

\section{Reversible and persistent CaMKII binding to NR2B in vitro} and in HEK cells

The observed reversible and persistent postsynaptic recruitment of CaMKII in neurons suggest different modes of interaction with its synaptic binding partner(s). Given that NR2B appears to be a key activity-dependent recruiter of CaMKII to postsynaptic sites (Bayer et al., 2001), we examined whether the receptor is capable of binding CaMKII with both reversible and persistent modes, using an in vitro binding assay of CaMKII $\alpha$ to immobilized GSTNR2B-C (Bayer et al., 2001). The amount of NR2B-bound CaMKII was determined after different times of $\mathrm{Ca}^{2+} / \mathrm{CaM}$ induced binding, followed by washes with either $\mathrm{Ca}^{2+} / \mathrm{CaM}$ or EGTA (Fig. $3 A, B$ ). Significantly more CaMKII $\alpha$ remained bound after $\mathrm{Ca}^{2+} / \mathrm{CaM}$ washes compared with EGTA washes but only in the early phase of the binding reaction $(<5 \mathrm{~min})$. After more extended binding times (5-45 min), inclusion of $\mathrm{Ca}^{2+}$ / $\mathrm{CaM}$ or EGTA in the washes no longer affected the amount of NR2B-bound kinase. Thus, the interaction of CaMKII $\alpha$ with NR2B is initially reversible but becomes $\mathrm{Ca}^{2+} / \mathrm{CaM}$ independent after longer binding, as observed for synaptic CaMKII translocation in neurons. Furthermore, this long-lasting binding interaction was independent of T286 phosphorylation, because the binding assays were performed in the absence of ATP.

To assess whether both modes of binding between CaMKII and NR2B also occurred with the full-length receptor inside live cells, we coexpressed both partners in HEK cells. Under these live-cell conditions, GFP-CaMKII $\alpha$ was reported to translocate to NR2B after an ionomycin-induced rise in intracellular $\left[\mathrm{Ca}^{2+}\right]$ (Bayer et al., 2001; Hudmon et al., 2005). Figure 3B shows an example of HEK cells cotransfected with NR2B and T286A-GFPCaMKII $\alpha$. Without stimulation, the cells show a diffuse pattern of GFP-CaMKII $\alpha$ fluorescence but with nuclear exclusion. After $\mathrm{Ca}^{2+}$ /ionomycin stimulation, the kinase translocated to form a punctate pattern within 1.5-3 min (Fig. 3C) but only when coexpressed with NR2B (Fig. $5 A$ ). When the $\mathrm{Ca}^{2+}$ stimulation was brief ( $2 \mathrm{~min}$ ), the punctate pattern completely reversed within 15 min of wash in EGTA ( $n=28$ cells) and, in most cases, within 5 $\min$ ( 23 of 28 cells). However, after a second stimulation of $6 \mathrm{~min}$, the punctate pattern persisted during EGTA perfusion for $20 \mathrm{~min}$ 

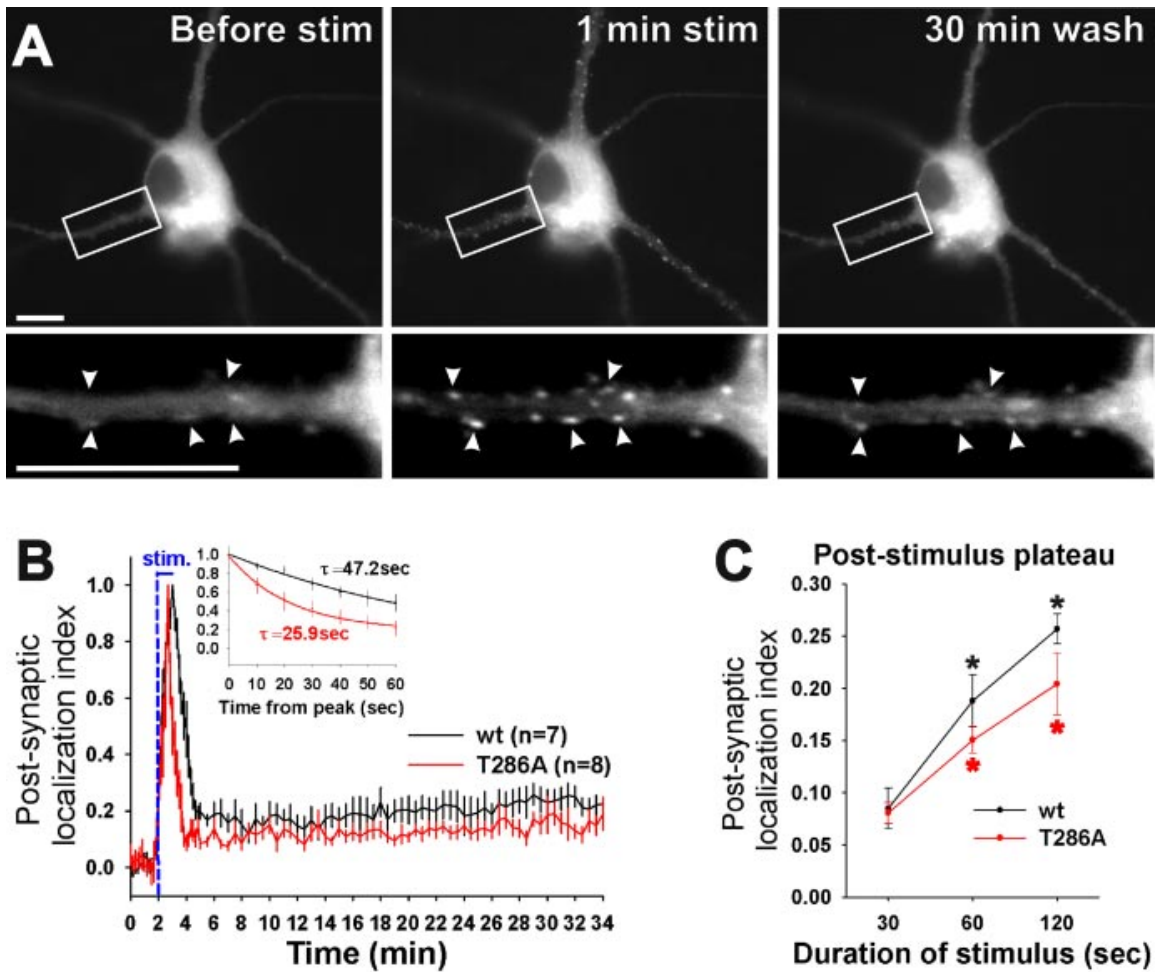

Duration of stimulus (sec)

Figure 2. Stimulus-induced transition from reversible to persistent synaptic CaMKII localization. $\boldsymbol{A}$, Time lapse images of GFP-CaMKII $\alpha$ in a neuron preincubated with AP-5. Arrowheads point to examples of synapses in which GFP-CaMKII $\alpha$ accumulated during the 1 min glutamate/glycine stimulation (stim) and persisted after the 30 min wash. Scale bars, $10 \mu \mathrm{m}$. $\boldsymbol{B}$, Mean ( \pm SEM) postsynaptic localization index of wild-type (wt) and T286A GFP-CaMKII $\alpha$ in neurons treated as in $A$. The initial dissociation curves (inset) for both wild type and T286A differed significantly from pooled data ( $p<0.002 ; F$ test). C, Effect of stimulation time on the poststimulation plateau of postsynaptic localization index of CaMKII. Mean ( \pm SEM; $n=7-9$ ) plateaus were determined between 15 and 30 min of washout. The asterisk indicates wild type and T286A differed significantly at 60 and 120 s from their 30 s time point $\left({ }^{*} p<0.005 ; t\right.$ test). Persistent plateaus of wt and T286A differed significantly from pooled data only at $120 \mathrm{~s}$ ( $p<0.005 ;$ F test).
A

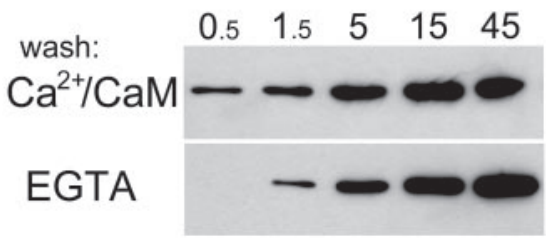

B

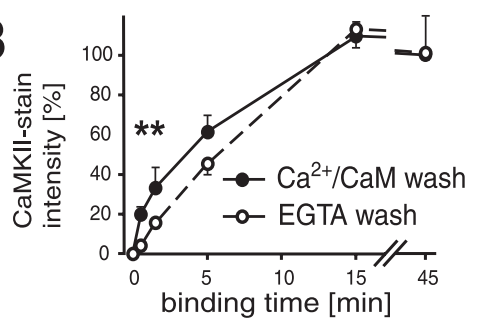

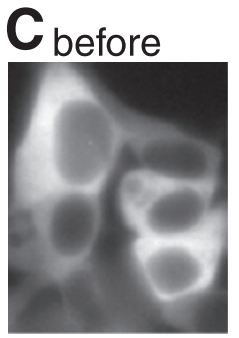
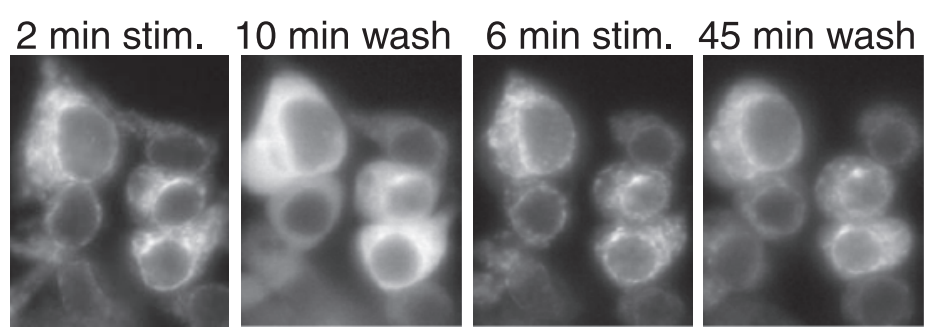

Figure 3. $\mathrm{Ca}^{2+}$-dependent and -independent states of CaMKIII $\alpha$ interaction with NR2B in vitro and in HEK cells. $A_{,}$B , CaMKII $\alpha$ was allowed to bind to immobilized GST-NR2B-C for various times, as indicated, at room temperature in the presence of $\mathrm{Ca}^{2+}$ / CaM. Then, the complexes were washed either with $\mathrm{Ca}^{2+} / \mathrm{CaM}$ or EGTA. $A$, Bound CaMKIl $\alpha$ is detected by immunoblotting of eluted protein. $\boldsymbol{B}$, CaMKIII $\alpha$ binding under the different conditions was compared by densitometry using NIH Image (means \pm $\mathrm{SEM} ; n=6)$. The asterisks indicate wash conditions that yielded significantly different CaMKII binding after $0.5 \min (p<0.005$; $t$ test) and $1.5 \mathrm{~min}$ ( $p<0.05 ; t$ test). C, Localization of GFP-CaMKII $\alpha$-T286A in living HEK cells cotransfected with NR2B changes after stimulation (stim.) with $\mathrm{Ca}^{2+} /$ ionomycin. Localization before and after two rounds of stimulation with subsequent EGTA washes is shown; stimulation times ( 2 and $6 \mathrm{~min}$ ) and wash times ( 10 and $45 \mathrm{~min}$ ) are indicated. Note the appearance of punctated fluorescence after the stimuli, which persisted after longer $(6 \mathrm{~min})$ stimulation.
( $n=28$ cells $)$ and, in most cases, for at least $45 \mathrm{~min}$ ( 21 of 28 cells). These experiments were performed using the T286A mutant to control for possible effect of autophosphorylation; however, similar results were obtained with GFP-CaMKII $\alpha$ wild-type: the punctate pattern reversed after short stimulation $(n=25)$ but persisted after extended stimulation $(n=20)$. Thus, translocation of CaMKII to NR2B in HEK cells shows a stimulation timedependent transition from a reversible to a persistent mode, both for CaMKII $\alpha$ wildtype and the autophosphorylationincompetent T286A mutant.

It should be noted that extended ionomycin treatment of HEK cells can lead to the formation of GFP-CaMKII clusters also in the absence of NR2B. However, such clusters show a distinct morphology from the pattern induced in the presence of NR2B and take more time to form (data not shown) (but see Hudmon et al., 2005). The time course of formation of such NR2B-independent clusters depends on the extracellular buffer and did not occur until 10 min of ionomycin under the conditions used here (data not shown). Furthermore, the persistent binding of CaMKII to NR2B during prolonged washes in the absence of $\mathrm{Ca}^{2+}$ contrasted from the CaMKII cluster formation in the absence of NR2B, which was fully reversible within a few minutes under such conditions (Hudmon et al., 2005).

\section{Mapping the NR2B interaction surface on CaMKII}

As a first step to better understand the mechanism underlying the dual modes of CaMKII binding to NR2B, we determined the region of CaMKII that is involved in the binding to NR2B by mutational analysis. We tested a set of CaMKII $\alpha$ mutants (19) and all CaMKII isoforms (4) for binding to the NR2B C-tail in our CaMKII overlay assay (Fig. 4). For all isoforms $(\alpha$, $\beta, \gamma_{\mathrm{B}}$, and $\delta_{\mathrm{A}}$ ), which differ at 45 amino acid positions, binding to NR2B-C was induced by stimulation with $\mathrm{Ca}^{2+} / \mathrm{CaM}$ without requirement of autophosphorylation (Fig. 4A). Once the binding was fully established, the interaction was no longer dependent on $\mathrm{Ca}^{2+} / \mathrm{CaM}$, because the isoforms remained bound during washes with EGTA. The same was observed for all but four of the point mutants (Fig. 4B): only F98K, E139R, I205K, and W237K showed significantly impaired binding. All other tested point mutants (K42M, E99K/ D100K, E105K, E109R, D111R, K148E, F173K, V208E, Y210R, E236K, D238R, V240D, and E243R) showed NR2B bind- 
ing similar to CaMKII $\alpha$ wild type. In Figure $4 C$, the position of the mutations are colored in yellow (impair NR2B binding) and green (do not impair binding) on three views of a CaMKII kinase domain model (Yang and Schulman, 1999); amino acid differences between the isoforms are colored in aqua.

Binding of CaMKII variants to fulllength NR2B was then tested in HEK cells (Fig. 5). In particular, the other major neuronal isoform, CaMKII $\beta$, and the four CaMKII $\alpha$ mutants impaired for in vitro binding to NR2B C-tail were examined. Translocation was observed for both the CaMKII $\alpha$ and $\beta$ isoforms (Fig. 5A). Because of the interaction of inactive CaMKII $\beta$ with F-actin, this isoform typically exhibited a distribution overlapping with cortical actin in unstimulated cells (Shen et al., 1998; Fink et al., 2003). After ionomycin treatment, the GFP-CaMKII $\beta$ quickly dispersed from such localization to form the same punctate pattern seen with the $\alpha$ isoform (Fig. 5A). In contrast, none of the $\alpha$ isoform mutants with impaired NR2B binding in vitro showed any NR2B-dependent translocation in HEK cells after 6 min of stimulation, except for a weak translocation of the W237K mutant (Fig. 5B). A punctate pattern for the W237K mutant was observed in only one of 85 cells within 3 min of stimulation, a time when translocation of the wild type was essentially completely established. After 6 min of stimulation, the W237K mutant translocated in 10 of 67 cells.

It is worth mentioning that the kinase domain of the four mutants is functionally intact, because they showed catalytic activity in a previous study (Yang and Schulman, 1999). However, two (F98K and E139R) showed reduced substrate affinity, because the mutations are in a substrate binding site (Yang and Schulman, 1999). Two of the mutants are partially autonomous (F98K and W237K) (Yang and Schulman, 1999), indicating partial disruption of autoinhibitory interactions. Disruption of autoinhibition itself does not abolish interaction with NR2B, because four other partially autonomous mutants (Yang and Schulman, 1999) did not show reduced NR2B binding (K148E, D238R, E243R, and T286D).

\section{Reduced synaptic targeting of NR2B binding-impaired CaMKII mutants}

We showed previously that the I205K mutant of CaMKII is impaired for activity-dependent postsynaptic translocation (Bayer et al., 2001). The identification of three additional CaMKII mutants with deficiencies for NR2B binding prompted us to examine whether they too were impaired for postsynaptic targeting. Indeed, all NR2B binding-impaired mutants showed clearly reduced postsynaptic translocation in transfected hippocampal neurons (Fig. 6). The extent of impairment for postsynaptic translocation of the mutants and for their binding to NR2B in vitro and in HEK cells appeared correlated, with CaMKII $\alpha$ W237K showing the mildest effect. Residual translocation of the NR2B-binding impaired mutants in neurons (CaMKII $\alpha$ F98K, I205K, E139R, and W237K) may be because of residual interac- tion with NR2B, interaction with additional synaptic proteins, or partial cotargeting in heteromers with the endogenous wild-type CaMKII. We also observed that monomeric GFP-CaMKII (1326) failed to accumulate postsynaptically (Fig. 6). This result is consistent with the fact that monomeric CaMKII also failed to stably bind to immobilized NR2B in vitro (data not shown) (but see Strack et al., 2000a), although the interaction of individual kinase subunits with NR2B peptides in solution does not appear to be dependent on holoenzyme structure (see below) (Fig. 8D).

\section{Peptide studies implicate the kinase domain T-site for} persistent binding to NR2B

Our mutational analysis points to two sites on CaMKII that may be involved in binding to NR2B. First, the substrate-binding site (S-site), where F98 and E139 reside and, second, the T286 binding site (T-site), where I205 and W237 reside (Fig. 7). To further examine the role of these sites in NR2B binding, we determined the effect of S- and T-site binding peptides on CaMKII interaction with NR2B in vitro (Fig. 8). Syntide is a CaMKII substrate peptide that should only interact with the S-site. Surprisingly, syntide did not block CaMKII binding to NR2B, not even at high concentrations (0.15-1.2 mM) (Fig. $8 A, C$ ). In contrast, AC3 and a peptide derived from the CaMKII binding site on NR2B (N2B-l) [compare Strack and Colbran (1998) and Bayer et al. (2001)] both interfered with the interaction (Fig. 8A). AC3 is derived from the CaMKII sequence around T286 and thus should be able to interact both with the S-site (as T286 is a CaMKII substrate) and with the T-site (to which T286 binds in the inactive state). Thus, blocking the T-site of CaMKII, in addition to the $\mathrm{S}$-site, interfered with binding to NR2B, whereas blocking the S-site alone was not sufficient.

The persistence of CaMKII binding to NR2B-C after removal of $\mathrm{Ca}^{2+} / \mathrm{CaM}$ suggested a very stable interaction between the 

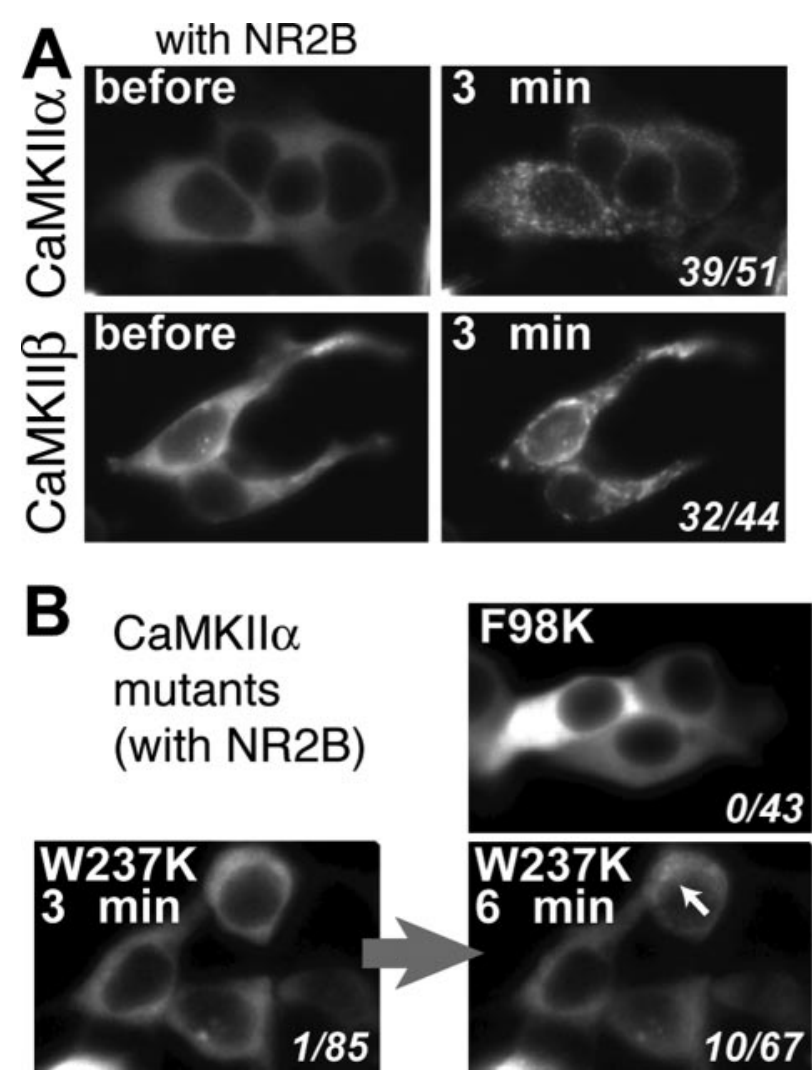

Figure 5. Impaired translocation of CaMKII mutants to NR2B in HEK cells. GFP-CaMKII isoforms or mutants were coexpressed

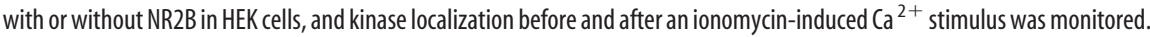
Representative cells are shown. The number of cells with translocating kinase per number of cells monitored (32-85) is indicated for each condition in the lower right corner of the corresponding panel. $\boldsymbol{A}$, CaMKII $\alpha$ and $\beta$ wild-type translocate in an NR2Bdependent manner. $\boldsymbol{B}$, The four CaMKII $\alpha$ mutants with impaired NR2B-C-binding in vitro show impaired translocation in HEK cells coexpressing NR2B. Pictures were taken 6 min after stimulation unless indicated otherwise. Only the W237K mutant showed any NR2B-dependent translocation.
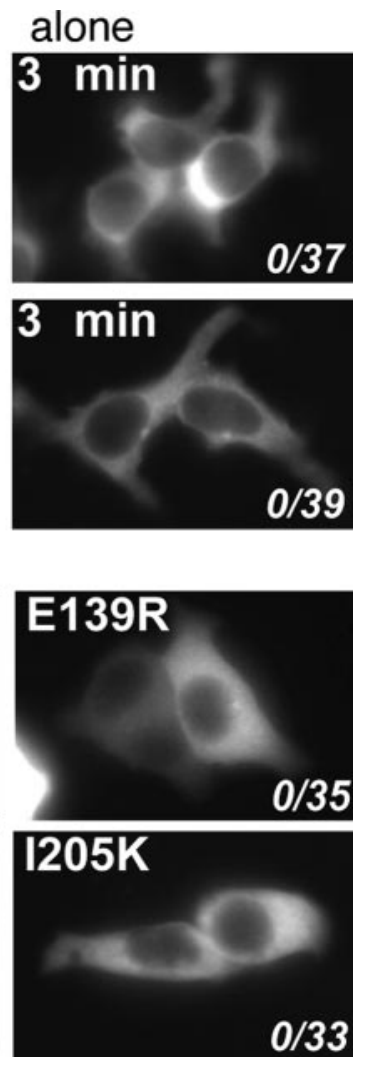

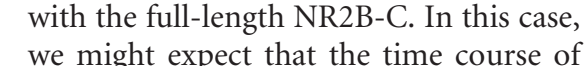
we might expect hat the time course of CaMKII binding to NR2B-C would be affected by N2B-s. In fact, preincubation of CaMKII with $150 \mu \mathrm{M}$ N2B-s in the presence of $\mathrm{Ca}^{2+} / \mathrm{CaM}$ accelerated subsequent binding to NR2B (Fig. $8 E$ ). The preincubation with $\mathrm{N} 2 \mathrm{~B}-\mathrm{s}$ even allowed binding in the absence of $\mathrm{Ca}^{2+} / \mathrm{CaM}$, indicating that it kept the kinase in an open conformation without completely blocking the NR2B binding surface. Syntide did not abolish the requirement for $\mathrm{Ca}^{2+} / \mathrm{CaM}$ but also accelerated binding. Together, the data suggest that initial occupation of the kinase S-site is essential to further promote a $\mathrm{Ca}^{2+} / \mathrm{CaM}$-induced open conformation that then allows access to the T-site. S-site occupation by peptides may circumvent requirement for initial S-site binding of NR2B and enable direct access to the T-site, which mediates the persistent binding mode. proteins. If so, we would predict that competing peptides would not be able to separate such an interaction once it is formed. Thus, we allowed CaMKII to bind to NR2B-C and then added AC3 or N2B-1. Figure $8 B$ shows that neither peptide was able to release the bound kinase from the receptor, consistent with a stable CaMKII-NR2B interaction.

The core region on NR2B and the peptide N2B-1 (NR2B 1259-1310) that binds to CaMKII is likely within NR2B 12891310 (Bayer et al., 2001; Strack et al., 2000a). We thus tested a corresponding peptide, N2B-s (NR2B 1289-1310), and observed that it interfered with CaMKII binding to NR2B in vitro (Fig. $8 C$ ). However, higher concentrations of N2B-s $(>150 \mu \mathrm{M})$ compared with N2B-1 were required, suggesting that amino acids 12591289 on the receptor may help to stabilize CaMKII interactions with the neighboring amino acids 1289-1310.

The NR2B-derived peptides N2B-l and N2B-s induced similar autonomous kinase activity for both CaMKII holoenzymes and monomeric kinase domains (CaMKII 1-316; contains the regulatory region and is subject to regulation by $\mathrm{Ca}^{2+} / \mathrm{CaM}$ ) (Fig. $8 D$ ). This indicated that the CaMKII kinase domain is not only necessary (see mutational analysis in Fig. 4) but also sufficient for interaction with an individual binding site on NR2B. However, for immobilized NR2B-C, no binding of monomeric CaMKII was detected in vitro (data not shown) (but see Strack et al., 2000a). Thus, holoenzyme structure may be required to allow simultaneous interactions of several of its kinase subunits with receptor subunits, thereby enhancing apparent affinity. Consis-
T- but not S-site mutants abolish persistent synaptic translocation

Our model for a sequential transition from reversible to persistent CaMKII binding to NR2B (Fig. 7) predicts that CaMKII $\mathrm{S}$-site mutants should be impaired for the initial reversible binding, whereas T-site mutants should be impaired for the persistent plateau of binding. Some of the mutants impaired for NR2B binding exhibited partial but significant accumulation at postsynaptic sites (Fig. 6). Thus, we decided to monitor the time course of this process during and after a $1 \mathrm{~min}$ glutamate/glycine stimulus (Fig. 9) (images are shown in supplemental Fig. 2, available at www.jneurosci.org as supplemental material). Indeed, the S-site mutants (F98K and E139R) were impaired for the initial peak translocation, which was completely abolished for the F98K mutant. The E139R mutant showed significantly reduced peak of translocation when compared with wild type (Fig. 9A). To evaluate the extent of long-lasting postsynaptic accumulation of this mutant, we rescaled this peak to that of wild type (Fig. 9B). The rescaled persistent plateau phases of E139R and wild type were indistinguishable, consistent with the model that the S-site mediates the initial contact but not the persistent binding. In contrast, the T-site mutants (I205K and W237K) showed essentially no persistent plateau, as expected from our model. However, their initial peak translocation was also reduced. This may indicate reversible T-site binding as a possible intermediate state in the transition from reversible to persistent binding. Peak translocation was least impaired for the W237K mutant, as expected 
(Figs. 5, 6), whereas I205K showed similar or stronger impairment when compared with the S-site mutant E139R. This may indicate that 1205 participates not only in persistent $\mathrm{T}$-site binding but also in the initial reversible interaction with NR2B. I205 is immediately adjacent to the S-site (Fig. 7A) and S-site binding may place NR2B residues N1296 or L1298 in a position that would allow hydrophobic interaction with I205 (Fig. 7B).

\section{Discussion}

Synaptic CaMKII activity is important for several forms of neuronal plasticity that underlie learning and memory (Silva et al., 1992; Lisman et al., 2002). We demonstrated here that stimulation of neurons with glutamate can trigger two modes of synaptic CaMKII binding (reversible and persistent). Both binding modes can be reconstituted with NR2B in nonneuronal cells and in an in vitro binding assay. The model in Figure 7 describes the transition from an initially transient $\mathrm{Ca}^{2+} / \mathrm{CaM}$ dependent interaction to a more stable $\mathrm{Ca}^{2+} / \mathrm{CaM}$-independent binding that also prolongs an active state of CaMKII. Such activity-dependent incorporation of CaMKII into postsynaptic sites may play a role in structural and functional synapse maturation during development and in learning and memory.

Based on our mutational analysis, two adjacent sites on the kinase domain of CaMKII, termed S-site and T-site, are required for the binding to NR2B. The regulatory region around T286 (CaMKII 272-293) interacts with the T-site of the same subunit in the basal state; after stimulation with $\mathrm{Ca}^{2+} / \mathrm{CaM}$, it becomes accessible to the S-site of a neighboring subunit. The CaMKII binding site on NR2B (around S1303) (Strack and Colbran, 1998; Bayer et al., 2001) is homologous to this regulatory region (around T286) and interacts with similar kinase surfaces in our model (Fig. 7). $\mathrm{Ca}^{2+} /$ $\mathrm{CaM}$ is required to displace the regulatory region from the $\mathrm{S}$-site and allow access of NR2B. This initial weak S-site occupation would then allow access to the T-site, where a more stable interaction with NR2B can be formed. Such interaction at the T-site is not dependent on $\mathrm{Ca}^{2+} / \mathrm{CaM}$ anymore and maintains partial kinase activity by keeping the regulatory region displaced. This model readily explains why mutations not only in the $\mathrm{T}$-site but also in the S-site impaired CaMKII binding to NR2B, although an S-site binding peptide did not block the interaction. It also explains both the initial $\mathrm{Ca}^{2+} / \mathrm{CaM}-$ dependent reversible binding followed by a more persistent interaction. The time delay in transition may be provided by dissociation and reassociation of the weak S-site binding until
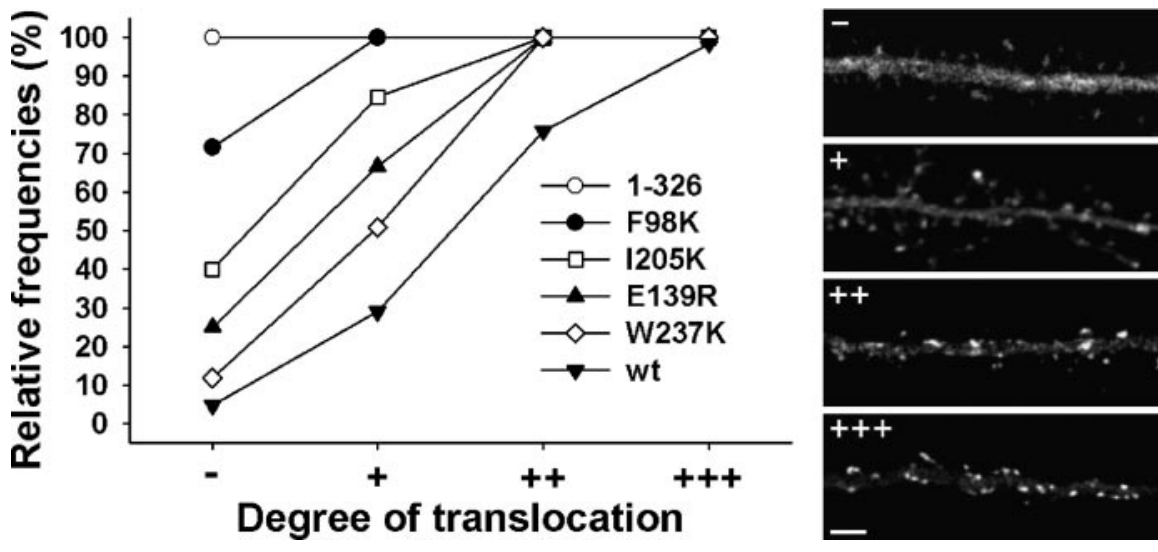

Figure 6. CaMKII $\alpha$ mutants with impaired NR2B binding show reduced postsynaptic localization. Relative frequency plot of postsynaptic localization of GFP-CaMKIl $\alpha$ wild type (wt) and mutants after a 1 min glutamate/glycine stimulation and an immediate fixation (neurons cultured as in Fig. 16). 1-326 is a monomeric CaMKIl $\alpha$ mutant. The right panels show examples of the dendrite categories used for scores ( - to +++ ). Every transfected neuron (14 DIV; $40-80$ per coverslip; $n=2$ ) was scored for each GFP-CaMKII $\alpha$ construct tested. Scale bar, $5 \mu \mathrm{m}$.
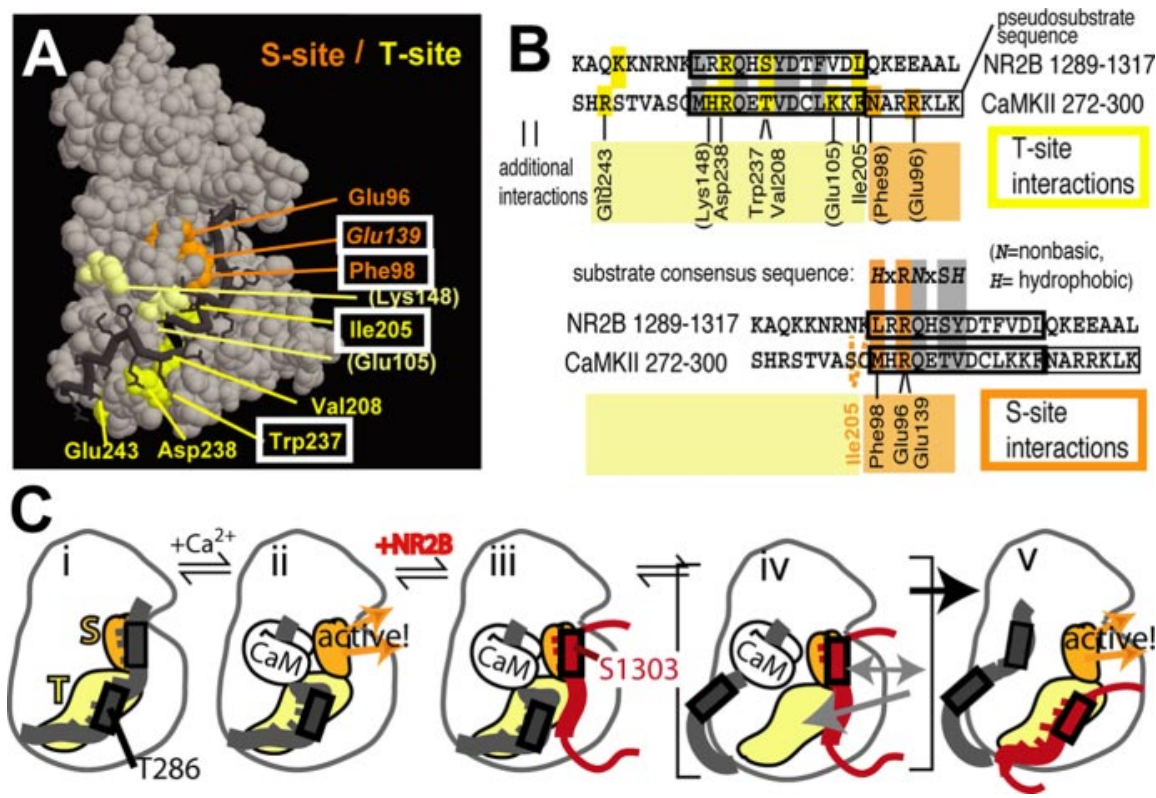

Figure 7. The NR2B-binding surface on CaMKIl is involved in autoregulation. $\boldsymbol{A}$, The residues implicated in the interaction with the autoregulatory region (shown as trace) are marked in this model of a kinase domain. Orange, Substrate binding site (S-site); yellow, T286 interacting site (T-site); boxed area, mutations that impaired NR2B binding. B, Alignment of the CaMKIl $\alpha$ autoregulatory region and the binding region on NR2B. Proposed T- and S-site interactions are marked in yellow and orange, respectively. The autoregulatory region of CaMKII interacts with the kinase domain of the same subunit as indicated in the top panel or with a neighboring subunit during T286 autophosphorylation as indicated in the bottom panel. Possible NR2B-specific additional S-site interactions of CaMKIII 205 are indicated by dashed orange lines. C, Models for biphasic interaction of a CaMKII kinase domain with NR2B. i, Basal state; ii, $\mathrm{Ca}^{2+} /$ CaM allows S-site access; iii, initial S-site binding of NR2B is required for T-site access (but can be circumvented by peptides occupying the $S$-site); iv, dissociation-reassociation provides stimulus time-dependent step; v, T-site binding involves more amino acids and is persistent.

stable T-site binding occurs. $\mathrm{Ca}^{2+} / \mathrm{CaM}$-induced binding followed by $\mathrm{Ca}^{2+} / \mathrm{CaM}$-independent autonomous activity of the bound CaMKII has been described for NR2B (Bayer et al., 2001) and for the eag potassium channel in Drosophila (Sun et al., 2004). If both mechanisms involve a similar transition from S- to T-site binding, eag-derived peptides should not only generate autonomous activity (through $\mathrm{T}$-site binding) but also decrease $\mathrm{Ca}^{2+} / \mathrm{CaM}$-activated activity (through S-site binding), as observed previously for NR2B-derived peptides (Bayer et al., 2001). 


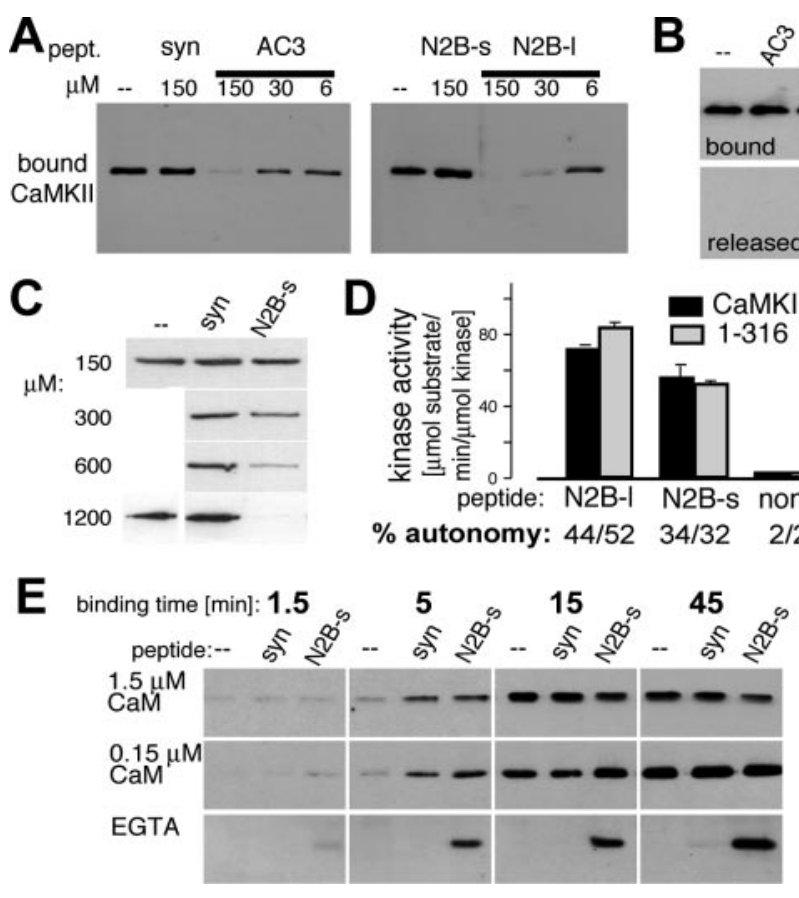

Figure 8. Effects of T- and S-site binding peptides on CaMKII $\alpha$ interaction with NR2B. $\boldsymbol{A}$, CaMKII $\alpha(0.2 \mu \mathrm{M})$ was incubated with different peptides (pept.) before the binding reaction to immobilized NR2B-C. Bound kinase was detected by immunoblotting the eluted protein. Syntide (syn) binds to the kinase $\mathrm{S}$-site, whereas $\mathrm{AC} 3$ can interact with both the $\mathrm{S}$-site and the T-site. N2B-I and N2B-s are derived from amino acids 1259-1310 and 1289-1310 of NR2B, respectively. $\boldsymbol{B}$, CaMKII was allowed to bind to immobilized NR2B-C; then, different peptides were added and incubated for $1 \mathrm{~h}$. Essentially, all of the kinase remained bound (top), and no kinase was detected in the supernatant (bottom). C, N2B-s (NR2B1289-1310) but not syntide affects CaMKII-NR2B interaction at high concentration. D, Autonomous kinase activity (means \pm SEM) of CaMKII $\alpha$ holoenzymes (CaMKII wt) and monomers (1-316) are affected similarly by the NR2B-derived peptides. Kinase/peptide interaction was enabled by $\mathrm{Ca}^{2+} / \mathrm{CaM}$ before the addition of EGTA. Autonomy is expressed as a percentage of the activity stimulated by $\mathrm{Ca}^{2+} / \mathrm{CaM}$ (in presence of peptide). $\boldsymbol{E}$, Time course of CaMKIl $\alpha$ binding to NR2B-C. Kinase, peptides, and $\mathrm{Ca}^{2+} / \mathrm{CaM}$ were preincubated for $8 \mathrm{~min}$. Bottom, CaM was dissociated from the kinase by EGTA before the binding reaction. Binding reactions were done at $4^{\circ} \mathrm{C}$ to slow down the kinetics.

NR2B peptides in solution induced autonomous activity equally well for kinase domain monomers and for multimeric holoenzymes, and mutations within the kinase domain abolished NR2B binding. Thus, the kinase domain mediates the interaction with NR2B, as suggested also by previous studies (Strack et al., 2000a; Bayer et al., 2001). However, only CaMKII holoenzymes, not kinase domain monomers, were found to bind to immobilized NR2B in vitro (data not shown) (but see Strack et al., 2000a) and to translocate to synapses in neurons. This could be explained by the dissociation step in our model. Simultaneous binding of multiple kinase domains of a holoenzyme to different NR2B molecules would keep the kinase in place to allow T-site reassociation after S-site dissociation. In neurons, this could explain why CaMKII translocates only to synaptic NMDARs, where they are more clustered.

Regulated binding of CaMKII to NR2B as a mechanism for synaptic CaMKII translocation in neurons is supported by the observations that both are induced by $\mathrm{Ca}^{2+} / \mathrm{CaM}$, do not require autophosphorylation (but can be enhanced by it), and show a transition from reversible to persistent interaction. Additionally, the four NR2B binding-deficient kinase mutants are also impaired for synaptic translocation. Additional evi-
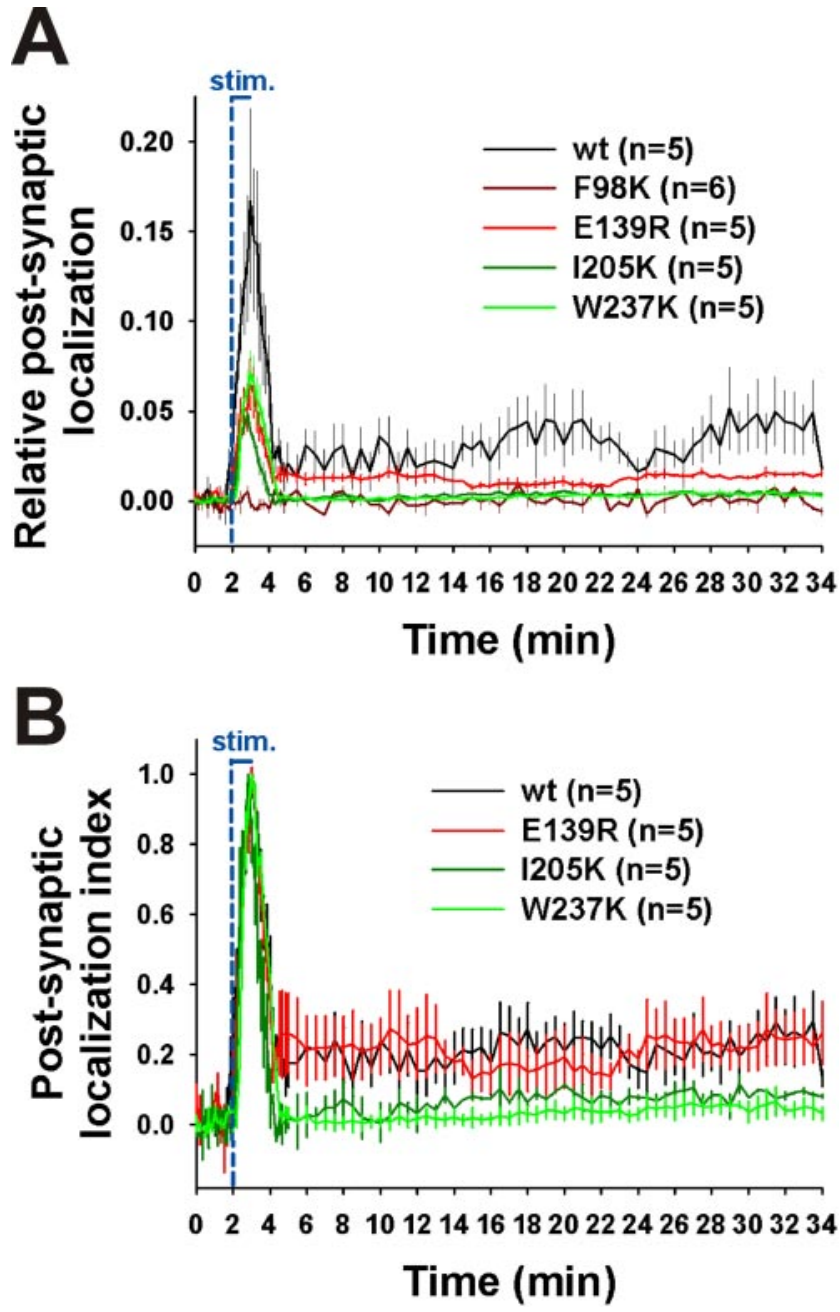

Figure 9. Effect of $\mathrm{S}$ - and T-site mutations on the transient and persistent postsynaptic translocation of CaMKIl $\alpha$ after a 1 min glutamate/glycine stimulus. $\boldsymbol{A}$, Mean ( \pm SEM) postsynaptic localization of wild type (wt) and mutant GFP-CaMKIll $\alpha$ relative to basal state (averaged over the first $2 \mathrm{~min}$ ) measured before, during, and after stimulation (stim.) (sample images are shown in supplemental Fig. 2, available at www.jneurosci.org as supplemental material). Statistical differences ( $t$ test) for the peak values compared with wt $(0.167 \pm$ $0.051)$ are $p<0.024($ (I205K, $0.049 \pm 0.003), p<0.042(E 139 R, 0.065 \pm 0.014)$, and $p<$ 0.056 (W237K, $0.071 \pm 0.012$ ). $\boldsymbol{B}$, Mean ( \pm SEM) postsynaptic localization index of wt and mutant GFP-CaMKII $\alpha$ in neurons treated as in $\boldsymbol{A}$. Data from $\boldsymbol{A}$ are rescaled from 0 (basal postsynaptic localization state, averaged over the first $2 \mathrm{~min}$ ) to 1 (maximal postsynaptic localization) to compare the postsynaptic dissociation of the different mutants and wt CaMKII after the stimulus. The E139R mutant also exhibited a long-lasting plateau of postsynaptic enrichment after the stimulus. The statistical differences ( $t$ test) for the mean index from 15 to 30 min of wash compared with wt $(0.218 \pm 0.011)$ are $p<0.006$ (W237K, $0.034 \pm 0.003)$, $p<0.042$ (I205K, $0.064 \pm 0.004)$, and $p>0.1$ (E139R, $0.195 \pm 0.011)$.

dence supporting a role of NR2B as a direct recruiter of CaMKII to the synapse could come from neuronal cultures from mutant mice lacking the NR2B cytoplasmic C terminus. However, these mice die around birth (Sprengel et al., 1998), and the major changes in NR2B-dependent overall postsynaptic organization would complicate the interpretation of such experiment. Even transient knockdown of NR2B by RNAi was shown to cause spine loss and reductions in NR2A, NR1, and GluR1 surface expression (Kim et al., 2005). Furthermore, NR2B has been shown to be critical in providing spine $\mathrm{Ca}^{2+}$ after glutamate stimulation (Sobczyk et al., 2005). Disrupted postsynaptic CaMKII targeting after NR2B deletion would be expected, primarily because of altered synaptic structure 
and/or $\mathrm{Ca}^{2+}$ signaling, and thus would not allow conclusions about NR2B functions as a direct CaMKII anchor.

Interactions with additional synaptic proteins such as NR1, NR2A, densin-180, $\alpha$-actinin, and CASK/Lin-2 may contribute to the postsynaptic targeting of the kinase, although regulation of their binding to CaMKII in vitro does not match the regulation of synaptic CaMKII targeting (Strack and Colbran, 1998; Gardoni et al., 1999; Strack et al., 2000b; Bayer et al., 2001; Walikonis et al., 2001; Leonard et al., 2002; Lu et al., 2003; Petersen et al., 2003) (for review, see Bayer and Schulman, 2001; Colbran, 2004). The multivalent nature of CaMKII holoenzymes should allow multiple simultaneous protein interactions at the synapse. This could involve simultaneous interaction with two NR2B molecules or with additional binding partners such as NR1, densin-180, or other already synaptically localized CaMKII holoenzymes. Indeed, CaMKII selfassociation may contribute to reversible postsynaptic recruitment of the kinase (Hudmon et al., 2005). Abolishing one such interaction may be sufficient to interfere with synaptic CaMKII targeting. For other synaptic proteins, at least two targeting elements are indeed required for proper localization: PSD95 targeting involves PDZ domains and a palmitoylation site (El-Husseini et al., 2000), SAP97 targeting involves PDZ domains and a 4.1 interaction site (Rumbaugh et al., 2003), and AKAP79/150 targeting involves PIP2 and F-actin binding sites (Gomez et al., 2002). CaMKII incorporation into the PSD by different protein-protein interactions may serve distinct structural and catalytic roles. Thus, CaMKII interaction with synaptic proteins other than NR2B may be of functional importance even if not essential for targeting.

The observation that glutamate application causes a rapid postsynaptic accumulation of CaMKII (Shen and Meyer, 1999) was met with great interest but also some surprise, because CaMKII is generally perceived as a major component of mature glutamatergic synapses even under basal synaptic activity (for review, see Kennedy, 2000). Indeed, we found GFPCaMKII $\alpha$ to be persistently located at synapses in 12- to 14 -dold hippocampal cultures, but chronically blocking NMDAR activity prevented such localization. Thus, our results indicate a transition from reversible to persistent NMDAR-dependent translocation as a mechanism to achieve CaMKII localization to mature synapses also under basal activity but dependent on past stimulation. CaMKII may become favorably localized to active synapses; the initial reversibility of the translocation could generate a threshold for the degree or frequency of neuronal activity required. As such, CaMKII could serve as a synaptic tag involved in the regulation of plasticity (Martin and Kosik, 2002) or may promote maturation of active synapses. Recent findings support that CaMKII persistently accumulates at synapses after chemical LTP induction (Otmakhov et al., 2004). Additionally, the NR2B-specific CaMKII binding site was found to be essential for LTP enhancement by NR2B overexpression (Barria and Malinow, 2004). Recent attempts at inhibiting specifically NR2A or NR2B in LTP protocols have yielded different results on various preparations (Liu et al., 2004; Massey et al., 2004; Berberich et al., 2005; Weitlauf et al., 2005). Conceivably, one key function of NR2B-containing receptors in LTP would be the recruitment and maintenance of CaMKII in the PSD, before the critical LTP-inducing activation of NR2A-containing receptors.

What are the synaptic substrates of NR2B-bound autonomous CaMKII? CaMKII can phosphorylate and regulate the AMPAR subunit GluR1 (Derkach et al., 1999) as well as the
AMPAR auxiliary protein stargazin (Tomita et al., 2005). However, because CaMKII is a $12-14$ meric holoenzyme of $\sim 20$ nM diameter (Kolodziej et al., 2000; Hoelz et al., 2003), it is likely that this phosphorylation involves the unbound subunits of the NR2B-bound holoenzyme, and therefore should still require a $\mathrm{Ca}^{2+} / \mathrm{CaM}$ stimulus. This re-emphasizes how an NR2B-dependent recruitment of CaMKII may serve as a synaptic tag (i.e., as a preceding step in a CaMKII-dependent phosphorylation of a postsynaptic target that is triggered by a subsequent synaptic transmission event). In contrast, NR2B can be phosphorylated directly by autonomous activity of bound CaMKII (Bayer et al., 2001), which may serve to maintain the receptor in the phosphorylated state. Indeed, there is evidence that CaMKII activity can potentiate NMDAR currents (Kitamura et al., 1993; Kolaj et al., 1994). Several other CaMKII substrates are found in tight complexes with NMDARs (Yoshimura et al., 2000), and some may be directly phosphorylated by the autonomous activity of an NR2Bbound kinase subunit. This may include the scaffolding protein PSD95 and the ras GTPase activating protein SynGAP (Chen et al., 1998; Kim et al., 1998). Indeed, SynGAP is regulated by CaMKII (Oh et al., 2004) and is critical for neuronal development and plasticity (Kim et al., 1998; Komiyama et al., 2002). Both $\mathrm{Ca}^{2+} / \mathrm{CaM}$-dependent and autonomous activities of CaMKII have been implicated in the induction and maintenance of LTP (for review, see Lisman and McIntyre, 2001; Lisman et al., 2002). Thus, elucidating the mechanisms of synaptic CaMKII action will contribute to understanding learning and memory at a molecular level.

Note added in proof. The study of Barria and Malinow is now published (Barria and Malinow, 2005). A crystal structure of a CaMKII kinase domain is now available (Rosenberg et al., 2005); there is no conflict between this structure and the binding model proposed here.

\section{References}

Barria AS, Malinow R (2004) NMDA receptor subunits and synaptic plasticity. Soc Neurosci Abstr 30:55.20.

Barria A, Malinow R (2005) NMDA receptor subunit composition controls synaptic plasticity by regulating binding to CaMKII. Neuron 48:289-301.

Bayer KU, Schulman H (2001) Regulation of signal transduction by protein targeting: the case for CaMKII. Biochem Biophys Res Commun 289:917-923.

Bayer KU, Harbers K, Schulman H (1998) alphaKAP is an anchoring protein for a novel CaM kinase II isoform in skeletal muscle. EMBO J 17:5598-5605.

Bayer KU, De Koninck P, Leonard AS, Hell JW, Schulman H (2001) Interaction with the NMDA receptor locks CaMKII in an active conformation. Nature 411:801-805.

Benke TA, Luthi A, Isaac JT, Collingridge GL (1998) Modulation of AMPA receptor unitary conductance by synaptic activity. Nature 393:793-797.

Berberich S, Punnakkal P, Jensen V, Pawlak V, Seeburg PH, Hvalby O, Kohr G (2005) Lack of NMDA receptor subtype selectivity for hippocampal long-term potentiation. J Neurosci 25:6907-6910.

Bradshaw JM, Hudmon A, Schulman H (2002) Chemical quenched flow kinetic studies indicate an intraholoenzyme autophosphorylation mechanism for $\mathrm{Ca}^{2+} /$ calmodulin-dependent protein kinase II. J Biol Chem 277:20991-20998.

Chen HJ, Rojas-Soto M, Oguni A, Kennedy MB (1998) A synaptic RasGTPase activating protein (p135 SynGAP) inhibited by CaM kinase II. Neuron 20:895-904.

Chen HX, Otmakhov N, Strack S, Colbran RJ, Lisman JE (2001) Is persistent activity of calcium/calmodulin-dependent kinase required for the maintenance of LTP? J Neurophysiol 85:1368-1376. 
Colbran RJ (2004) Targeting of calcium/calmodulin-dependent protein kinase II. Biochem J 378:1-16.

Colbran RJ, Brown AM (2004) Calcium/calmodulin-dependent protein kinase II and synaptic plasticity. Curr Opin Neurobiol 14:318-327.

Derkach V, Barria A, Soderling TR (1999) $\mathrm{Ca}^{2+} /$ calmodulin-kinase II enhances channel conductance of alpha-amino-3-hydroxy-5-methyl-4isoxazolepropionate type glutamate receptors. Proc Natl Acad Sci USA 96:3269-3274.

El-Husseini AE, Craven SE, Chetkovich DM, Firestein BL, Schnell E, Aoki C, Bredt DS (2000) Dual palmitoylation of PSD-95 mediates its vesiculotubular sorting, postsynaptic targeting, and ion channel clustering. J Cell Biol 148:159-172.

Fink CC, Bayer KU, Myers JW, Ferrell Jr JE, Schulman H, Meyer T (2003) Selective regulation of neurite extension and synapse formation by the beta but not the alpha isoform of CaMKII. Neuron 39:283-297.

Fukunaga K, Muller D, Ohmitsu M, Bako E, DePaoli-Roach AA, Miyamoto E (2000) Decreased protein phosphatase 2A activity in hippocampal longterm potentiation. J Neurochem 74:807-817.

Gardoni F, Schrama LH, van Dalen JJ, Gispen WH, Cattabeni F, Di Luca M (1999) AlphaCaMKII binding to the C-terminal tail of NMDA receptor subunit NR2A and its modulation by autophosphorylation. FEBS Lett 456:394-398.

Gomez LL, Alam S, Smith KE, Horne E, Dell'Acqua ML (2002) Regulation of A-kinase anchoring protein 79/150-cAMP-dependent protein kinase postsynaptic targeting by NMDA receptor activation of calcineurin and remodeling of dendritic actin. J Neurosci 22:7027-7044.

Griffith LC (2004) Calcium/calmodulin-dependent protein kinase II: an unforgettable kinase. J Neurosci 24:8391-8393.

Hayashi Y, Shi SH, Esteban JA, Piccini A, Poncer JC, Malinow R (2000) Driving AMPA receptors into synapses by LTP and CaMKII: requirement for GluR1 and PDZ domain interaction. Science 287:2262-2267.

Hoelz A, Nairn AC, Kuriyan J (2003) Crystal structure of a tetradecameric assembly of the association domain of $\mathrm{Ca}^{2+} /$ calmodulin-dependent kinase II. Mol Cell 11:1241-1251.

Hudmon A, Lebel E, Roy H, Sik A, Schulman H, Waxham MN, De Koninck P (2005) A mechanism for $\mathrm{Ca}^{2+} /$ calmodulin-dependent protein kinase II clustering at synaptic and nonsynaptic sites based on self-association. J Neurosci 25:6971-6983.

Kennedy MB (2000) Signal-processing machines at the postsynaptic density. Science 290:750-754.

Kim JH, Liao D, Lau LF, Huganir RL (1998) SynGAP: a synaptic RasGAP that associates with the PSD-95/SAP90 protein family. Neuron 20:683-691.

Kim MJ, Dunah AW, Wang YT, Sheng M (2005) Differential roles of NR2Aand NR2B-containing NMDA receptors in Ras-ERK signaling and AMPA receptor trafficking. Neuron 46:745-760.

Kitamura Y, Miyazaki A, Yamanaka Y, Nomura Y (1993) Stimulatory effects of protein kinase C and calmodulin kinase II on $N$-methyl-D-aspartate receptor/channels in the postsynaptic density of rat brain. J Neurochem 61:100-109.

Kolaj M, Cerne R, Cheng G, Brickey DA, Randic M (1994) Alpha subunit of calcium/calmodulin-dependent protein kinase enhances excitatory amino acid and synaptic responses of rat spinal dorsal horn neurons. J Neurophysiol 72:2525-2531.

Kolodziej SJ, Hudmon A, Waxham MN, Stoops JK (2000) Threedimensional reconstructions of calcium/calmodulin-dependent (CaM) kinase IIalpha and truncated CaM kinase IIalpha reveal a unique organization for its structural core and functional domains. J Biol Chem 275:14354-14359.

Komiyama NH, Watabe AM, Carlisle HJ, Porter K, Charlesworth P, Monti J, Strathdee DJ, O'Carroll CM, Martin SJ, Morris RG, O'Dell TJ, Grant SG (2002) SynGAP regulates ERK/MAPK signaling, synaptic plasticity, and learning in the complex with postsynaptic density 95 and NMDA receptor. J Neurosci 22:9721-9732.

Leonard AS, Bayer KU, Merrill MA, Lim IA, Shea MA, Schulman H, Hell JW (2002) Regulation of calcium/calmodulin-dependent protein kinase II docking to $N$-methyl-D-aspartate receptors by calcium/calmodulin and alpha-actinin. J Biol Chem 277:48441-48448.

Lisman J, Schulman H, Cline H (2002) The molecular basis of CaMKII function in synaptic and behavioural memory. Nat Rev Neurosci 3:175-190.
Lisman JE, McIntyre CC (2001) Synaptic plasticity: a molecular memory switch. Curr Biol 11:R788-R791.

Liu L, Wong TP, Pozza MF, Lingenhoehl K, Wang Y, Sheng M, Auberson YP, Wang YT (2004) Role of NMDA receptor subtypes in governing the direction of hippocampal synaptic plasticity. Science 304:1021-1024.

Lu CS, Hodge JJ, Mehren J, Sun XX, Griffith LC (2003) Regulation of the $\mathrm{Ca}^{2+} / \mathrm{CaM}$-responsive pool of CaMKII by scaffold-dependent autophosphorylation. Neuron 40:1185-1197.

Malenka RC, Nicoll RA (1999) Long-term potentiation-a decade of progress? Science 285:1870-1874.

Martin KC, Kosik KS (2002) Synaptic tagging-who's it? Nat Rev Neurosci 3:813-820.

Massey PV, Johnson BE, Moult PR, Auberson YP, Brown MW, Molnar E, Collingridge GL, Bashir ZI (2004) Differential roles of NR2A and NR2B-containing NMDA receptors in cortical long-term potentiation and long-term depression. J Neurosci 24:7821-7828.

Oh JS, Manzerra P, Kennedy MB (2004) Regulation of the neuron-specific Ras GTPase-activating protein, synGAP, by $\mathrm{Ca}^{2+} /$ calmodulin-dependent protein kinase II. J Biol Chem 279:17980-17988.

Otmakhov N, Tao-Cheng JH, Carpenter S, Asrican B, Dosemeci A, Reese TS, Lisman J (2004) Persistent accumulation of calcium/calmodulindependent protein kinase II in dendritic spines after induction of NMDA receptor-dependent chemical long-term potentiation. J Neurosci 24:9324-9331.

Petersen JD, Chen X, Vinade L, Dosemeci A, Lisman JE, Reese TS (2003) Distribution of postsynaptic density (PSD)-95 and $\mathrm{Ca}^{2+}$ / calmodulin-dependent protein kinase II at the PSD. J Neurosci 23:11270-11278.

Rosenberg O, Deindl S, Sung R, Nairn A, Kuriyan J (2005) Structure of the autoinhibited kinase domain of CaMKII and SAXS analysis of the holoenzyme. Cell 123:849-860.

Rumbaugh G, Sia GM, Garner CC, Huganir RL (2003) Synapse-associated protein-97 isoform-specific regulation of surface AMPA receptors and synaptic function in cultured neurons. J Neurosci 23:4567-4576.

Shen K, Meyer T (1999) Dynamic control of CaMKII translocation and localization in hippocampal neurons by NMDA receptor stimulation. Science 284:162-166.

Shen K, Teruel MN, Subramanian K, Meyer T (1998) CaMKIIbeta functions as an F-actin targeting module that localizes CaMKIIalpha/beta heterooligomers to dendritic spines. Neuron 21:593-606.

Shen K, Teruel MN, Connor JH, Shenolikar S, Meyer T (2000) Molecular memory by reversible translocation of calcium/calmodulin-dependent protein kinase II. Nat Neurosci 3:881-886.

Silva AJ, Stevens CF, Tonegawa S, Wang Y (1992) Deficient hippocampal long-term potentiation in alpha-calcium-calmodulin kinase II mutant mice. Science 257:201-206.

Singla SI, Hudmon A, Goldberg JM, Smith JL, Schulman H (2001) Molecular characterization of calmodulin trapping by calcium/calmodulindependent protein kinase II. J Biol Chem 276:29353-29360.

Sobczyk A, Scheuss V, Svoboda K (2005) NMDA receptor subunitdependent $\left[\mathrm{Ca}^{2+}\right]$ signaling in individual hippocampal dendritic spines. J Neurosci 25:6037-6046.

Sprengel R, Suchanek B, Amico C, Brusa R, Burnashev N, Rozov A, Hvalby O, Jensen V, Paulsen O, Andersen P, Kim JJ, Thompson RF, Sun W, Webster LC, Grant SG, Eilers J, Konnerth A, Li J, McNamara JO, Seeburg PH (1998) Importance of the intracellular domain of NR2 subunits for NMDA receptor function in vivo. Cell 92:279-289.

Strack S, Colbran RJ (1998) Autophosphorylation-dependent targeting of calcium/calmodulin-dependent protein kinase II by the NR2B subunit of the N-methyl-D-aspartate receptor. J Biol Chem 273:20689-20692.

Strack S, Barban MA, Wadzinski BE, Colbran RJ (1997) Differential inactivation of postsynaptic density-associated and soluble $\mathrm{Ca}^{2+} /$ calmodulindependent protein kinase II by protein phosphatases 1 and 2A. J Neurochem 68:2119-2128.

Strack S, McNeill RB, Colbran RJ (2000a) Mechanism and regulation of calcium/calmodulin-dependent protein kinase II targeting to the NR2B subunit of the $N$-methyl-D-aspartate receptor. J Biol Chem 275:23798-23806.

Strack S, Robison AJ, Bass MA, Colbran RJ (2000b) Association of calcium/ calmodulin-dependent kinase II with developmentally regulated splice 
variants of the postsynaptic density protein densin-180. J Biol Chem 275:25061-25064.

Sun XX, Hodge JJ, Zhou Y, Nguyen M, Griffith LC (2004) The eag potassium channel binds and locally activates calcium/calmodulin-dependent protein kinase II. J Biol Chem 279:10206-10214.

Tomita S, Stein V, Stocker TJ, Nicoll RA, Bredt DS (2005) Bidirectional synaptic plasticity regulated by phosphorylation of stargazin-like TARPs. Neuron 45:269-277.

Walikonis RS, Oguni A, Khorosheva EM, Jeng CJ, Asuncion FJ, Kennedy MB (2001) Densin-180 forms a ternary complex with the (alpha)-subunit of $\mathrm{Ca}^{2+} /$ calmodulin-dependent protein kinase II and (alpha)-actinin. J Neurosci 21:423-433.

Weitlauf C, Honse Y, Auberson YP, Mishina M, Lovinger DM, Winder DG (2005) Activation of NR2A-containing NMDA receptors is not obliga- tory for NMDA receptor-dependent long-term potentiation. J Neurosci 25:8386-8390.

Yang E, Schulman H (1999) Structural examination of autoregulation of multifunctional calcium/calmodulin-dependent protein kinase II. J Biol Chem 274:26199-26208.

Yoshimura Y, Aoi C, Yamauchi T (2000) Investigation of protein substrates of $\mathrm{Ca}(2+) /$ calmodulin-dependent protein kinase II translocated to the postsynaptic density. Brain Res Mol Brain Res 81:118-128.

Zacharias DA, Violin JD, Newton AC, Tsien RY (2002) Partitioning of lipidmodified monomeric GFPs into membrane microdomains of live cells. Science 296:913-916.

Zhu JJ, Qin Y, Zhao M, Van Aelst L, Malinow R (2002) Ras and Rap control AMPA receptor trafficking during synaptic plasticity. Cell 110:443-455. 